\title{
Sequence and Analysis of Chromosome I of the Amitochondriate Intracellular Parasite Encephalitozoon cuniculi (Microspora)
}

\author{
Pierre Peyret, ${ }^{1,5}$ Michael D. Katinka, ${ }^{2}$ Simone Duprat, ${ }^{3}$ Francis Duffieux, ${ }^{1,4}$ \\ Valérie Barbe, ${ }^{3}$ Martin Barbazanges, ${ }^{1}$ Jean Weissenbach, ${ }^{2,3}$ William Saurin, ${ }^{2,3}$ \\ and Christian P. Vivarès ${ }^{1}$ \\ ${ }^{1}$ Equipe de Parasitologie Moléculaire et Cellulaire, LBP, UMR CNRS 6023, Université Blaise Pascal, 63177 Aubière Cedex, \\ France; ${ }^{2}$ UMR CNRS 8030, CP 5706, 91057 Evry Cedex, France; ${ }^{3}$ Genoscope, CP 5706, 91057 Evry Cedex, France
}

\begin{abstract}
A DNA sequencing program was applied to the small $(<3 \mathrm{Mb})$ genome of the microsporidian Encephalitozoon cuniculi, an amitochondriate eukaryotic parasite of mammals, and the sequence of the smallest chromosome was determined. The $\sim 224-\mathrm{kb}$ E. cuniculi chromosome I exhibits a dyad symmetry characterized by two identical 37-kb subtelomeric regions which are divergently oriented and extend just downstream of the inverted copies of an 8-kb duplicated cluster of six genes. Each subtelomeric region comprises a single 16S-23S rDNA transcription unit, flanked by various tandemly repeated sequences, and ends with $\sim 1 \mathrm{~kb}$ of heterogeneous telomeric repeats. The central (or core) region of the chromosome harbors a highly compact arrangement of 132 potential protein-coding genes plus two tRNA genes (one gene per $1.14 \mathrm{~kb}$ ). Most genes occur as single copies with no identified introns. Of these putative genes, only 53 could be assigned to known functions. A number of genes from the transcription and translation machineries as well as from other cellular processes display characteristic eukaryotic signatures or are clearly eukaryote-specific.
\end{abstract}

[The sequence data described in this paper have been submitted to the EMBL data library under accession no. AL 391737.]

The eukaryotic phylum termed Microspora is composed of more than 1000 amitochondriate unicellular species which are all obligate intracellular parasites found throughout the entire animal world, including humans. Many of the Microspora species exhibit a wide host range, parasitizing a large number of mammalian species. The clinical importance of these opportunistic pathogens in man was discovered in immunodepressed patients with the emergence of AIDS and through the evolution of surgical and medical technologies, mainly in transplantation and cancer chemotherapy involving immunosuppression. Recently, microsporidiosis also has been detected in immunocompetent patients (Sandfort et al. 1994; Raynaud et al. 1998). Evidence for waterborne transmission of several species of microsporidia has been reported (Dowd et al. 1998) and the zoonotic potential of Encephalitozoon cuniculi genotypes in mammals has been demonstrated (Mathis et al. 1997).

\footnotetext{
${ }^{4}$ Present address: Laboratoire de Résonance Magnétique Nucléaire, Département de Chimie Structurale et Organique, Ecole Polytechnique, 91128 Palaiseau Cedex, France.

${ }^{5}$ Corresponding author.

E-MAIL pierre.peyret@lbp.univ-bpclermont.fr; FAX 33-473407670.

Article and publication are at www.genome.org/cgi/doi/10.1101/ gr.164301.
}

Species of the Encephalitozoon genus were shown to harbor the smallest known eukaryote nuclear genomes with a size of $<3 \mathrm{Mb}$ (Biderre et al. 1995, 1999b). However, little is known about the organization of microsporidian DNA sequences, except for the rDNA transcription unit, which was first claimed to have a prokaryote-like organization because of the small size of rRNAs (16S and 23S) and fusion of the 5.8S sequence to the 5' end of 23S coding region (Curgy et al. 1980; Vossbrinck and Woese 1986). Models of secondary structure clearly showed a strong reduction of several domains within the microsporidian 23S rRNA but typical eukaryotic features of this molecule were retained (De Rijk et al. 1998; Peyretaillade et al. 1998a; Van de Peer et al. 2000). A few protein-coding genes also have been sequenced. To the list published by Weiss and Vossbrinck (1999), can be added genes encoding the largest subunit of the RNA Pol II (Hirt et al. 1999), a TATA box-binding protein (Fast et al. 1999), and a spore wall protein (Bohne et al. 2000). Most sequencing data were used for phylogenetic purposes and led to controversial hypotheses about the evolutionary origin of microsporidia. Using phylogenetic analyses based on the sequences of small-subunit rRNA and two translation elongation factors (Vossbrinck et al. 1987; Kamaishi et al. 1996a,b), these amitochondriate organ- 
isms are viewed as early-diverging eukaryotes. However, the concept that microsporidia could represent primitively amitochondriate eukaryotes was not supported by the finding of microsporidian genes encoding a mitochondrial HSP70 homolog (Germot et al. 1996; Hirt et al. 1997; Peyretaillade et al. 1998b). In addition, phylogenetic trees constructed with four different protein-coding genes were all suggestive of a late origin and a relationship with fungi (Edlind et al. 1996; Keeling and Doolitle 1996; Fast et al. 1999; Hirt et al. 1999). Only three genes encoding microsporidiaspecific structural proteins have been reported (Delbac et al. 1998; Keohane et al. 1998; Bohne et al. 2000).

The analysis of a 4.3-kb sequence contig from chromosome I provided preliminary information on the chromosomal arrangement of protein-coding genes, revealing a strong reduction of intergenic spacers (Duffieux et al. 1998). The occurrence of gene length variability has also been documented through the interspecific comparison of microsporidian rRNA sequences (Weiss and Vossbrinck 1999) and suggests that strong selection pressures may have driven the $E$. cuniculi into nuclear genome close to the minimal gene complement for a "selfish" eukaryote dependent on a host organism. To test this concept and to obtain new insights into microsporidian biology and evolution, a whole genome sequencing project was initiated in 1998. Here, we report the complete sequence of $E$. $c u$ niculi chromosome I and highlight some features of its organization and gene content.

A

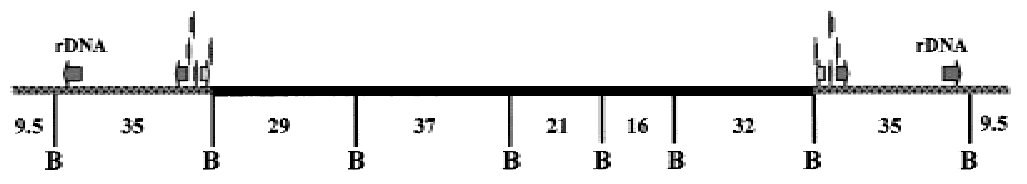

$14 \mathrm{~kb}$

B

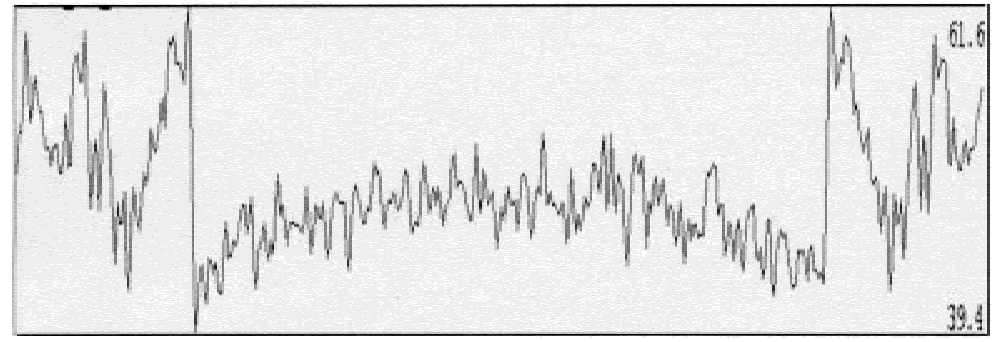

Figure 1 Scheme of Encephalitozoon cuniculi chromosome I organization. (A) The symmetrical organization of chromosome extremities, the location of the two rDNA transcription units in the subtelomeric region (gray), and the presence of a six putative CDSs duplication at the junction of the core and subtelomeric region (see Results) are illustrated. The central black trait depicts the core region composed mostly of unique genes. B represents BssHII restriction sites used for physical mapping and sequence confirmation in this study. $(B) \mathrm{G}+\mathrm{C}$ percentage along the chromosome calculated in a 500-nt window with 100-nt progression increments. The highest and lowest $G+C$ percentage are shown on the right of the panel.

\section{RESULTS}

\section{General Features}

The complete sequence of E. cuniculi chromosome I was determined using a whole shotgun strategy followed by targeted gap closure and polishing. The proposed numbering in nucleotides of the chromosome for a precise analysis, 199,956 base-pairs (bp), extends from the 3 ' end of the large subunit (LSU) rDNA gene (he $3^{\prime}$ end of the second LSU rDNA ass the telomeric repeats nor the multiple subtelomeric repeats in proximal ends.

Because the highly repeated sequences are very ort, their assembly cannot be considered to reflect peats chall sequence organization. The telomeric resituated $23 \mathrm{~S}$ rDNA gene (Fig. 1A) as deduced by physical mapping (Brugère et al. 2000a). As shown in Figure 1A, the chromosome is composed of two distinct regions: an $\sim 150-\mathrm{kb}$ central region composed essentially of unique sequences and comprising most, if not all, protein encoding sequences (CDS1-CDS132), and two $\sim 37-\mathrm{kb}$ subtelomeric divergent regions, each including one NA transcription unit composed of a small and a rge rDNA gene, the 5' of the latter being fused to $3^{\prime}$ of the $5.8 \mathrm{~S}$ gene. The $\mathrm{G}+\mathrm{C}$ content is $47.30 \%$ for the coding region, slightly lower $(43 \%)$ in the intergenic regions and higher $(52.85 \%)$ in the overall telomeric and subtelomeric regions (Fig. 1B). Analysis using the motif discovery program MEME revealed $\mathrm{A}+\mathrm{T}$ rich consensus transcription promoting sequences (AAATGACA; ATAAAAAA) located in the $50 \mathrm{bp}$ region upstream of the putative ATG in the 53 genes encoding proteins with known functions (see below). The presence at the junction of the subtelomeric region and the core region of a strict duplication of an 8-kb cluster comprising six potential genes including aminopeptidase, dihydrofolate reductase, thymidylate synthase, serine hydroxymethyl transferase, an $\mathrm{ABC}$ transporter, and a yet unknown protein is also observed. This gene duplication extends the dyad symmetry of the chromosome extremities to over $>45 \mathrm{~kb}$.

\section{Telomere Repeats, Telomere Associated Sequences, and Tandem Repeats}

Telomeric sequences were identified in a telomere-enriched library constructed as described in Methods. The insert extremi- 
ties were sequenced and in $\sim 12 \%$ of the clones, repetitive sequences were detected next to the NotI adapter used for cloning. The repetitive elements are composed of alternate G(A or G)GCCT(C or T)CT, GAGCCTTGTTT, and GAGACGCAGTGTTGCCAGGATG. In the pBAM recombinant library (genomic DNA digested by CviJI, see Methods), $\sim 0.1 \%$ of the clones exhibited the same repeats but none were found in the pBAC library (genomic DNA digested by Sau3A, see Methods). This could be explained by the fact that the CviJI cuts in PuGCPy, i.e., in sequences within telomeric repeats. To verify that these repeats were indeed telomeric, they were used as probes in Southern blot hybridization experiments, following Bal31 digestion kinetics experiments (see Methods). As shown in Figure 2, the genomic DNA that hybridizes with the repeats probe was completely degraded by the Bal31 exonuclease in 7.5-8 min at digestion rates of $\sim 155 \mathrm{bp} / \mathrm{min}$. This demonstrates both that the repeats are telomeric and that the size of the region is between $1100 \mathrm{bp}$ and $1200 \mathrm{bp}$.

It should be emphasized that our study of the telomeric repeats was not restricted to chromosome I alone. The organization of chromosome ends was analyzed through both physical mapping (Brugère et al. 2000a) and sequencing of other chromosome ends. This demonstrated very limited if any variation in the subtelomeric sequences with an identical distance between the BssHII site and the chromosome end. Thus, the telomere repeat probes hybridized to all 11 chromosomes in Southern blot experiments (data not shown) and the compact size of the bands revealed in the blots after Bal31 digestion of all 22 chromosome

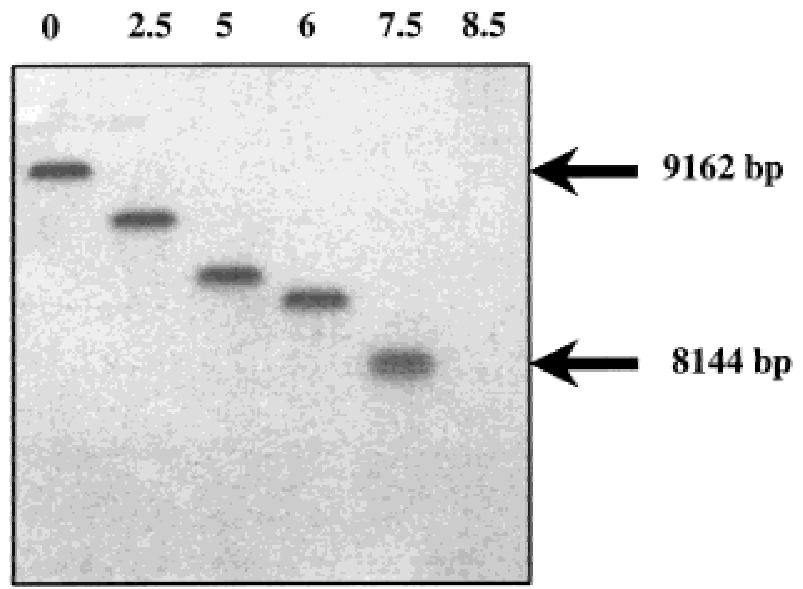

Figure 2 Bal-31 digestion blot analysis of telomere repeats. Encephalitozoon cuniculi total genomic DNA was digested by Bal31 nuclease for $0,2.5,5,6,7.5,8.5 \mathrm{~min}$ (lanes $1-6$, respectively) and subsequently digested with BssHII. This was followed by sizefractionation on agarose gel electrophoresis and Southern blotting onto a nylon membrane. The blot was then hybridized with ${ }^{32} \mathrm{P}$-labeled telomere repeat oligonucleotides as probes and autoradiographed for $5 \mathrm{~h}$.

\begin{tabular}{|c|c|c|c|}
\hline Indices & $\begin{array}{l}\text { Period } \\
\text { size }\end{array}$ & $\begin{array}{l}\text { Copy } \\
\text { number }\end{array}$ & $\begin{array}{l}\text { Percent } \\
\text { matches }\end{array}$ \\
\hline $4051-4121$ & 30 & 2.4 & 97 \\
\hline $4493-4519$ & 7 & 3.9 & 100 \\
\hline $5112-5225$ & 14 & 8.1 & 96 \\
\hline $5265-5291$ & 10 & 2.7 & 100 \\
\hline $5489-5516$ & 14 & 2.0 & 100 \\
\hline $6763-6798$ & 12 & 3.0 & 91 \\
\hline 7881-7921 & 20 & 2.0 & 100 \\
\hline $8255-8291$ & 19 & 1.9 & 100 \\
\hline $16,002-16,050$ & 9 & 5.4 & 95 \\
\hline $16,002-16,050$ & 18 & 2.7 & 93 \\
\hline $18,599-18,659$ & 18 & 3.4 & 93 \\
\hline
\end{tabular}

See text (Results) for details.

extremities indicates a low variability of repeat length ( $\leq 50 \mathrm{bp})$.

The search for tandem repeats in the subtelomeric region situated between the rDNA cluster and the core [to the first coding DNA sequence (CDS) encoding aminopeptidase] was performed using the Tandem Repeats Finder Program and reveals a highly structured region with 11 repeat types shown in Table 1 . The largest repeat is 30-bp long and is present in 2.4 copies; the smaller one is the ACACACC present in 3.9 copies. Two regions devoid of tandem repeats (8291-16002; 16050-18599) could be potentially transcribed and eight putative open reading frames (ORFs) without significant identities to known proteins were detected by Glimmer. A strict conservation of this organization is shown in the other extremity. Only five single nucleotide polymorphisms (position 10193, 10233, 10372, $10620,10630)$ were found. The size of the subtelomeric region between the telomere repeats and the rDNA cluster obtained after sequence assembly was of only $3.5 \mathrm{~kb}$ instead of $\sim 9.5 \mathrm{~kb}$ deduced by physical mapping (Brugère et al. 2000a). This underestimation is attributable to the presence of short highly repetitive sequences, preventing proper assembly and limiting the interest of a precise description.

\section{Gene Content}

Using Glimmer as a tool for gene detection, 131 putative ORFs were identified as schematized in Figure 3. An additional ORF (CDS 95) was identified by the Prodom BLAST and Wise2 programs and encodes for a putative ring-box-like protein. The size of this CDS (99 amino acids) was below the detection threshold of Glimmer fixed at 100 amino acids. Other small ORFs with no homologies or characteristic signatures will remain undetected under these conditions. Genome analysis depicts a highly compact organization with a mean gene density of one gene per $1.14 \mathrm{~kb}$. Intergenic 


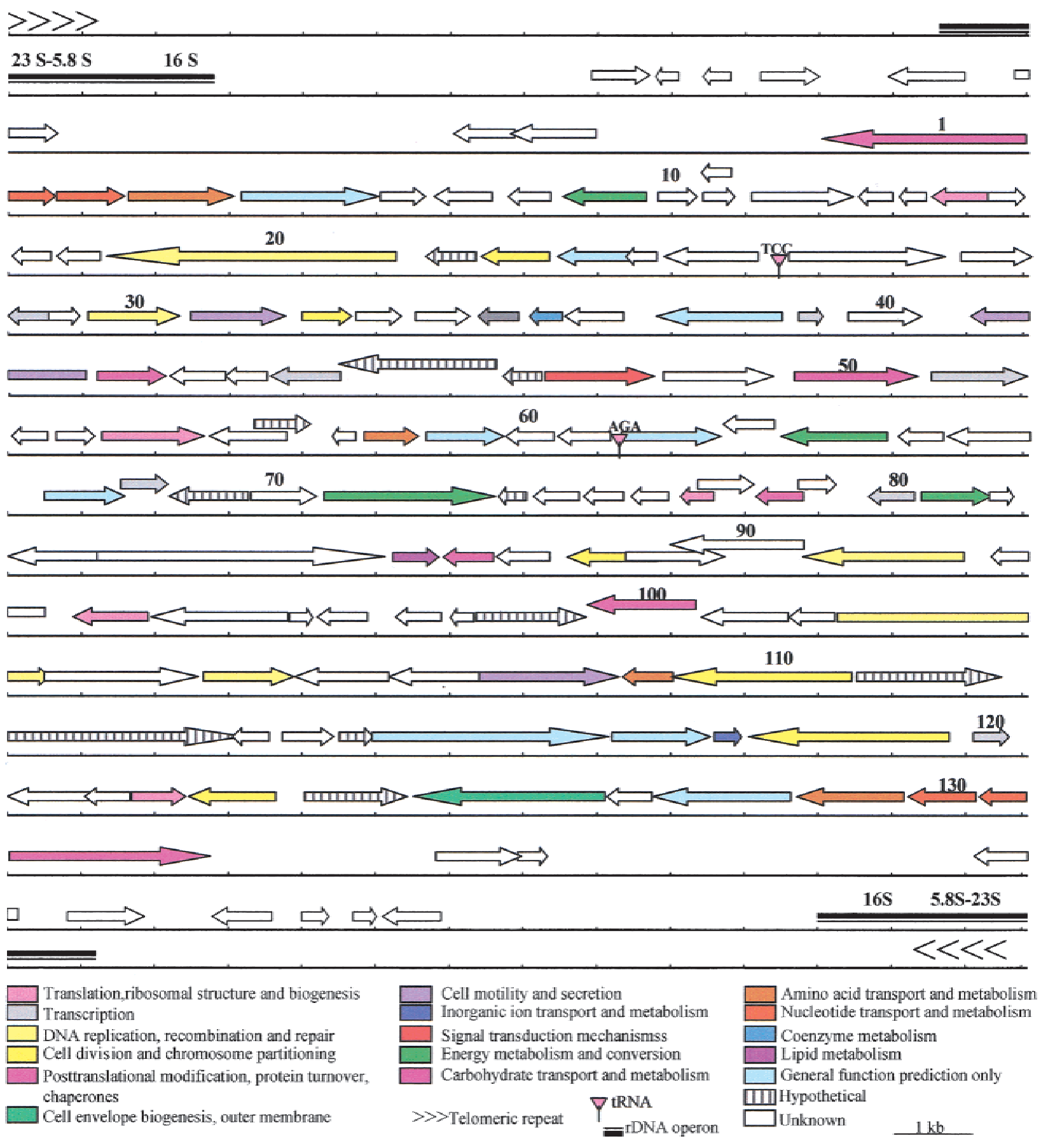

Figure 3 Putative gene map of Encephalitozoon cuniculi chromosome I. Predicted coding regions are shown with the arrows indicating the transcription orientation; the black box depicts the rDNA transcription unit; the chevrons depict the telomeres. Genes are color coded according to broad role categories as shown in the key.

regions are very small with a maximum of 639 bp between CDSs 40 and 41 and a mean distance of 116 bp. Some ORFs seem to overlap each other but in all such cases at least one of the ORFs remains ill-defined and potentially encodes a hypothetical protein with an undetermined function. Examples of possible overlaps were observed between a serine hydroxy methyl trans- ferase gene (CDSs 4 and 129) and thymidylate synthase (CDSs 3 and 130). However, even this possibility seems remote because multiple alignments using CLUSTAL W applied to the putative serine hydroxy methyl transferase gene indicate that the most probable initiation codon is located 196 amino acids downstream of the putative start codon determined by Glimmer. This un- 
likely overlap was therefore not presented in Figure 3. The number of ORFs is in the same range on both DNA strands with $44 \%$ (58 CDSs representing $66,876 \mathrm{bp}$ ) on the Watson strand (upper strand) and 56\% (74 CDSs representing $73,541 \mathrm{bp}$ ) on the Crick strand (lower strand). The largest CDS (CDS 20, 3752 bp) encodes a putative helicase with a molecular weight of 144,575 Da. CDS 84 likewise encodes a large protein $(141,454$ $\mathrm{Da}$ ) with an unknown function but containing five putative transmembrane domains. A total of 11 putative proteins harbor transmembrane domains. Among them, is chitin synthase (CDS 126), which must play a major role in spore wall formation in microsporidia. Analysis of the third largest protein $(115,974 \mathrm{Da})$ encoded by CDS 112 reveals the presence of a calciumbinding site suggesting a role in an as yet undetermined regulatory process. The CDSs coding for proteins with either putative or unknown functions represent $\sim 60 \%$ of the total ORFs identified. Table 2 presents a functional classification of the proteins encoded on chromosome I. We note a high proportion $(\sim 20 \%)$ of genes implicated in replication, transcription, and translation processes. Ten putative proteins with zinc-finger (CDSs 22, 28, 42, 59, 60, 62, 67, 95,

Table 2. Classification of E. cuniculi Genes According to Clusters of Orthologous Groups of Proteins (COGs)

\begin{tabular}{|c|c|c|c|c|c|}
\hline CDS\# & Gene description & \%ID & CDS\# & Gene description & $\%$ ID \\
\hline \multicolumn{3}{|c|}{ Translation, ribosomal structure and biogenesis } & \multicolumn{3}{|c|}{ Cell motility and secretion } \\
\hline 0016 & Ribosomal protein L8 & 68 & 0031 & Actin & 79 \\
\hline 0054 & Elongation factor 2 & 72 & 0041 & Myosin heavy chain & 43 \\
\hline 0076 & Ribosomal protein $\mathrm{S} 12$ & 47 & 0108 & Dynamin & 52 \\
\hline 0093 & Nucleolar protein p120 & 51 & Inorgar & on transport and metabolism & \\
\hline 0123 & snoRNP & 51 & 0118 & Putative frataxin & 59 \\
\hline & \multicolumn{3}{|c|}{ Signal transduction mechanisms } \\
\hline \multicolumn{3}{|c|}{ Clipper/cleavage and } & \multicolumn{3}{|c|}{ Energy metabolism and conversion } \\
\hline 0032 & Transcription factor & 69 & 0009 & Fructose bi-phosphate & \\
\hline \multirow[t]{2}{*}{0035} & \multirow{2}{*}{$\begin{array}{l}\text { RNA polymerase II } \\
\text { mediator }\end{array}$} & & & aldolase & 54 \\
\hline & & 54 & 0064 & Alpha, alpha-trehalose- & 65 \\
\hline 0039 & RNA binding protein & 57 & & phosphate synthase & \\
\hline 0045 & DNA-directed RNA pol I & 58 & 0071 & Trehalose-6-P phosphatase & 39 \\
\hline 0051 & Transcription factor IIH & 47 & 0081 & Aldose reductase & 55 \\
\hline 0068 & RNA binding protein & 49 & \multicolumn{3}{|c|}{ Carbohydrate transport and metabolism } \\
\hline 0080 & TBP-1 1 & 48 & 0050 & $\mathrm{~N}$-acetylglucosamine- & \\
\hline 0120 & TFIID subunit & 61 & & phosphate mutase & 55 \\
\hline \multirow{2}{*}{\multicolumn{3}{|c|}{ DNA replication, recombination }} & \multicolumn{3}{|c|}{ Amino acid transport and metabolism } \\
\hline & & & 0004 & Serine hydroxy methyl & \\
\hline 0020 & Helicase & 60 & & transferase & 67 \\
\hline 0030 & DNA repair protein & 41 & 0129 & Serine hydroxy methyl transferase & 67 \\
\hline 0091 & DNA repair helicase & 68 & & & \\
\hline \multirow[t]{2}{*}{0103} & Chromosome assembly & 41 & \multicolumn{3}{|c|}{ Nucleotide transport and metabolism } \\
\hline & protein & & 0002 & Dihydrofolate reductase & 52 \\
\hline 0105 & Replication factor C & 47 & 0003 & Thymidylate synthase & 73 \\
\hline \multicolumn{3}{|c|}{ Cell division and chromosome partitioning } & 0058 & Thymidine kinase & 52 \\
\hline 0022 & Putative cell division & 50 & 0109 & Guanylate kinase & 60 \\
\hline \multirow[t]{2}{*}{0088} & Putative microtubule & & 0130 & Thymidylate synthase & 73 \\
\hline & associated protein & 42 & 0131 & Dihydrofolate reductase & 52 \\
\hline \multirow[t]{2}{*}{0110} & Cell division cycle & & \multicolumn{3}{|c|}{ Coenzyme metabolism } \\
\hline & protein 48 homolog & 77 & 0036 & NIFU protein & 83 \\
\hline 0119 & Cell division cycle 42 & 52 & \multicolumn{3}{|c|}{ Lipid metabolism } \\
\hline 0124 & Septin homolog protein & 47 & 0085 & CDP-diacylglycerol- & \\
\hline \multirow{2}{*}{\multicolumn{3}{|c|}{$\begin{array}{l}\text { Posttranslational modification, protein turnover, } \\
\text { chaperones }\end{array}$}} & & inositol 3 phosphatidyl & 48 \\
\hline 0001 & & 47 & \multicolumn{3}{|c|}{ General function prediction only } \\
\hline 0042 & DNAJ like-protein & 52 & 0005 & $A B C$ transporter & 46 \\
\hline \multirow[t]{2}{*}{0078} & Ubiquitin-conjugating & & 0023 & Cell differentiation & 51 \\
\hline & enzyme & 56 & 0038 & Golgi protein & 57 \\
\hline \multirow[t]{2}{*}{0086} & Ubiquitin-conjugating & & 0059 & Zinc finger protein & 46 \\
\hline & enzyme & 59 & 0062 & Zinc finger protein & 44 \\
\hline 0100 & Serine protease & 49 & 0067 & Zinc finger protein & 72 \\
\hline 0132 & Aminopeptidase & 47 & 0116 & Coatomer protein & 48 \\
\hline \multicolumn{3}{|c|}{ Cell envelope biogenesis, outer membrane } & 0117 & WD-repeat protein & 45 \\
\hline 0126 & Chitin synthase & 65 & 0128 & $A B C$ transporter & 46 \\
\hline
\end{tabular}

Gene numerotation is identical to that shown in Fig. 3.

ID represents the percentage of identity relative to the most relevant database find. 
101, 106) or s-antigen (SWI3, ADA2, N-COR, and TFIIIB) domains are observed and probably function in regulatory mechanisms of nucleic acids synthesis. Contractile domains were identified in three putative proteins (CDSs 26, 41, 107) and could be related to the myosin family. Of the three sugar metabolism genes identified, two belong to the trehalose pathway (CDS 64 alpha, alpha-trehalose-phosphate synthase, and CDS 71 trehalose-6P phosphatase). Codon usage was studied in individual genes (putatively high and low expression rates) as well as for the whole ORF population. On the whole, the codon usage resembles that of a standard unicellular eukaryote (results not shown). Fifteen additional ORFs with no known homology were detected in the subtelomeric region by Glimmer and of these only eight CDSs that are not part of the tandem repeat sequences are shown in Figure 3. Two probable tRNA genes $(G l y, S e r)$ were detected by the tRNAscan-SE program and are located at nucleotide positions 50,585 and 88,026 , respectively. The tRNA ${ }^{\text {Ser }}$ gene contains an extra $\mathrm{U}$ residue between the acceptor and the D-loop stems, in position 10 of the classical cloverleaf model. No intron was detected in these two tRNA genes.

\section{DISCUSSION}

Large-scale sequencing in genomes from eukaryotic parasites to date is limited to two complete chromosomes from Plasmodium falciparum (Bowman et al. 1998; Gardner et al. 1998) and one from Leishmania major (Myler et al. 1999), and to a large contig from Trypanosoma cruzi (Andersson et al. 1998) and a high throughput EST project in Toxoplasma gondii (Ajioka et al. 1998). The characteristic feature of the chromosome structure of E. cuniculi is the highly symmetrical organization of the two subtelomeric regions that occupy almost one third of the chromosome length and consist of one rDNA unit with a closely associated cluster of six genes each. A similar organization has been described in the vestigial genome of a cryptomonad nucleomorph (Zauner et al. 2000) and of a chlorarachniophyte nucleomorph, with a centripetal orientation of the rDNA unit in the latter organism (Gilson and McFadden 1997). The telomeric repeats of the nucleomorph chromosomes of Guillardia theta $\left[(\mathrm{AG})_{7} \mathrm{AAG}_{6} \mathrm{~A}\right.$, Zauner et al. 2000] like those of a number of fungi $\left(\mathrm{C}_{2-3} \mathrm{ACA}_{1-6}\right.$ in Saccharomyces; $\mathrm{ACAC}_{2} \mathrm{ACATAC}_{2}$ $\mathrm{TA}_{2} \mathrm{TCA}_{3} \mathrm{TC}_{2} \mathrm{GA}$ in Kluyveromyces; and $\mathrm{C}_{1-6} \mathrm{G}_{0-1}$ $\mathrm{T}_{\mathrm{O}-1} \mathrm{GTA}_{1-2}$ in Schizosaccharomyces) differ from the standard 5-8 nucleotide repeats of other eukaryotes. In E. cuniculi, the telomeric repeats are also relatively complex but it would be premature to conclude some close phylogenetic relationship with the previous organisms.

The understanding of the sequence organization in the subtelomeric region around the rDNA unit will be of interest for precise localization of the sites of chromosomal rearrangement that have been predicted from studies on intraspecies karyotype variability (Biderre et al. 1999a; Brugère et al. 2000b). Moreover, the phenotype of some parasitic protozoans can be affected by subtelomeric rearrangements as demonstrated for knob formation and gametocyte production in P. falciparum (Pologe and Ravetech 1986; Day et al. 1993). As in $P$. falciparum and $P$. berghei, the E. cuniculi chromosome structure is characterized by the conservation of the two subtelomeric regions. Antigenic variation in Trypanosoma brucei is also linked to chromosome end reorganization by gene conversion (for review, see Pays and Nolan 1998). In Microsporidia, however, programmed rearrangements inducing phenotype variability have not yet been reported and extensive studies will be needed to understand their physiological functions (centromeres? replication origins? recombination hot-spots, etc.).

The genes in chromosome I of E. cuniculi are highly packed with a density of one gene per $1.14 \mathrm{~kb}$ which is higher than Saccharomyces cerevisiae (one per 2 kb; Goffeau et al. 1996), L. major (one per $3.26 \mathrm{~kb}$; Myler et al. 1999), P. falciparum (one per 4 kb; Gardner et al. 1998; Bowman et al. 1998), T. cruzi (one per 4.5 kb; Andersson et al. 1998) and C. elegans (one per 5 kb; The C. elegans Sequencing Consortium 1998). This denotes, at least in part, the scarcity of $E$. cuniculi introns. The CDS mean size, estimated at $1070 \mathrm{bp}$, partly reflects a reduction in the mean protein size. Proteins such as actin and ribosomal proteins remain highly conserved in length but some enzymes of intermediary metabolism appear to be greatly shortened, such as those involved in trehalose biosynthesis. The molecular weight for the trehalose-6-phosphate phosphatase of $S$. cerevisiae is $103 \mathrm{kDa}$ compared to $82 \mathrm{Da}$ for $E$. cuniculi. This is reminiscent of the previously described reduction in the $16 \mathrm{~S}$ and $23 \mathrm{~S}$ rRNA sequences (Curgy et al. 1980).

The gene content of chromosome I suggests some interesting physiological features. Two genes coding for enzymes implicated in trehalose biosynthesis (alpha, alpha-trehalose phosphate synthase, and trehalose-6P phosphatase) were found. Trehalose is known to represent a large fraction of stored carbohydrates in fungi. Increased osmolyte concentration through the cleavage of trehalose into two glucose molecules was proposed as responsible for the pressure increase required for initiating microsporidian spore germination, a crucial step for the entry of the parasite into a new host cell (Undeen 1990). It seems likely that this disaccharide also plays a role as a glucose energy reserve for possible degradation through a glycolysis pathway in this amitochondriate organism (Weidner et al. 1999). High concentrations of trehalose in spores of both aquatic and terrestrial microsporidian species 
(Undeen and Vander Meer 1999) may indicate a longterm energy storage facility due to its protective properties, which have been described by Singer and Lindquist (1998). Recently, Yfh1, a yeast homolog of mammalian frataxin, was found to be important in the efflux of iron from mitochondria (Radisky et al. 1999) and two other yeast proteins (NFU1 and ISU1) related to NifU protein play a role in iron homeostasis in assembly, insertion, and/or repair of mitochondrial Fe-S clusters (Schilke et al. 1999). Putative frataxin and NIFU protein identified on chromosome I would be valuable for studies on the evolution of iron homeostasis in amitochondriate organisms. Because of their involvement in the various microsporidian life stages, the presence of myosin, dynamin and actin, which are typical eukaryote genes on chromosome $\mathrm{I}$ is also of significant interest. In a recent electron microscope immunocytochemical study, actin was demonstrated to be located mainly at the periphery of the developmental cell stages including mature spores (Bigliardi et al. 1999). A possible involvement of actin in the biogenesis of the complex invasive apparatus, especially the long extrusome-like structure known as the polar tube, has been suggested.

Very little is known about microsporidian transcriptional processes. Only a single mRNA encoding a spore wall protein with $5^{\prime}$ and $3^{\prime}$ UTRs 9 and 165 nucleotides long, respectively, has been described in microsporidia (Bohne et al. 2000). Identification of a gene encoding a TATA binding protein and an A $+\mathrm{T}$ rich consensus sequence in intergenic regions emphasizes the probable transcriptional regulatory implications of TATA box recognition. No polycistronic gene organization like that of trypanosomatid and kinetoplastid protein-coding genes (Andersson et al. 1998; Myler et al. 1999) has been found and E. cuniculi chromosome I encodes mostly monocistronic transcription units. Only one gene cluster is observed, the two adjacent putative thymidylate synthase and dihydrofolate reductase genes. These two genes, which encode a monofunctional peptide, are independent in both fungi and animals but are fused in plants and protozoa (Beverly et al. 1986; Cella et al. 1988). One spliceosomal-type intron has been described in a ribosomal protein gene located on E. cuniculi chromosome X (Biderre et al. 1998) but no possible intron was detected in the chromosome I sequence. Indirect evidence that microsporidia harbor genes with introns was previously suggested by the discovery of divergent U2 snRNA in Vairimorpha necatrix (DiMaria et al. 1996) and more recently with U2 and U6 snRNA gene descriptions in Nosema locustae (Fast et al. 1998). However, cis-splicing does not seem a common phenomenon in microsporidia unlike $P$. falciparum chromosomes 2 and 3 in which half of the genes have been predicted to contain at least one intron. Other proto- zoans such as Paramecium aurelia or Tetrahymena thermophila contain a small number of genes with introns $(<1 \%)$. We cannot exclude however, the presence of short introns in-frame in $5^{\prime}$ and $3^{\prime}$ gene regions and characterization of cDNA will be of great help. A supernumerary $U$ base is observed in the $D$ stem of the tRNA $^{\text {Ser }}$ gene. Surprisingly, a tRNA ${ }^{\text {Ser }}$ of the cryptomonad nucleomorph bears two introns, the first of which (intron 1, 10 nucleotides) occupies a unique position in the D loop whereas intron 2 typically resides in the anticodon loop as observed in other eukaryotic tRNAs (Zauner et al. 2000). The first base of intron 1 of the nucleomorph $\mathrm{tRNA}^{\mathrm{Ser}}$ is a $U$ residue and could correspond to the supernumerary $U$ residue of $E$. cuniculi tRNA $^{\text {Ser }}$ which would hence be a remnant of an intron eliminated incompletely during evolution.

A better understanding of the microsporidian transcriptional and translational machineries as well as that of its metabolic pathways should greatly progress with the determination of the complete genome sequence and should accelerate drug discovery based on new therapeutic targets. Microsporidia infection is treated today by two drugs, albendazole and fumagillin, with limited success (Didier 1997). TNP-470, a semisynthetic analog of fumagillin of lesser toxicity, seems a promising treatment of some types of microsporidiosis (Coyle et al. 1998). Recently, methionine aminopeptidase- 2 was identified in yeast as the cellular target of fumagillin (Sin et al. 1997) and the threedimensional structure of the protein complexed to its fumagillin ligand determined (Liu et al. 1998). A methionine aminopeptidase is found on chromosome $\mathrm{X}$ of E. cuniculi and may contribute to structure-based microsporidiosis drug design. Genomics may lead to the revelation of new genes implicated in pathogenesis and relationships with host cells as well as to the development of better diagnostic tools and new treatments.

E. Cuniculi has been presumed to be a diploid organism and some evidence for allelic chromosomes of different size was derived from hybridization data with different isolates (Biderre et al. 1999a; Brugère et al. 2000b). In the strain I mouse isolate used for the systematic sequencing project, only chromosome III exhibits potential allelism deduced from differential migration in agarose gels. The absence of flagrant allelic variation and the minimal amount of sequence polymorphism within the chromosome I could be explained by frequent recombination between homologous chromosomes in the context of asexual reproduction. An identical situation has been described for chromosome I of L. major (Myler et al. 1999). No characteristic sequence or $(\mathrm{A}+\mathrm{T})$ rich region corresponding to a putative centromere has been identified on chromosome I. The sequencing of the whole E. cuniculi genome should in the near future clarify whether the 
low degree of gene redundancy on chromosome I also prevails in the 10 larger chromosomes. The identification of major potential metabolic pathways is expected and the extent of a possible loss of genetic information related to the parasitic life style will be evaluated.

\section{METHODS}

\section{Genome DNA Cloning, Nucleotide Sequencing and Sequence Validation}

The reference mouse isolate of E. cuniculi (GB-M1; Biderre et al. 1994, 1999a) used throughout this work was provided by Professor E.U. Canning (Imperial College of Science, Technology and Medicine, London, UK). Parasite cells were grown on Madin Darby Canine Kidney (MDCK) cells as described (Beauvais et al. 1994). E. cuniculi spores were isolated from infected cultures and DNA purified as described previously (Duffieux et al. 1998). Two libraries were constructed: (1) a $2.3 \times 10^{4}$ clone library in the plasmid vector BAM3 (Dr. Roland Heilig, unpubl. construction derived from pBluescript II KS ${ }^{+}$, Stratagene) harboring total genome DNA which was restricted randomly by $\mathrm{CviJI}$ into 3 -kb fragments that were inserted into the unique SmaI site, and (2) a $2 \times 10^{5}$ clone library using a slightly modified Bacterial Artificial Chromosome (BAC) vector, pBeloBAC11, in which randomly restricted Sau3A 20-30 $\mathrm{kb}$ fragments were inserted into the unique BamHI site. For the latter library, spores were embedded in agarose and following proteinase K lysis, DNA was purified by AFIGE (Asymmetric Field Inversion Gel Electrophoresis) pulsed field electrophoresis using a Fige Mapper (BioRad) apparatus. For both libraries recombinant material was electroporated into Escherichia coli K-12 DH10B electro-competent bacteria (GIBCOBRL, Life Technologies) in $0.1 \mathrm{~cm}$ cuvettes using a Micropulser apparatus (BioRad). Electroporation conditions were $17.5 \mathrm{kV} / \mathrm{cm}, 25 \mu \mathrm{F}$, and $200 \Omega$. Extraction of plasmid or BAC DNA and sequencing of the recombinant material ends were performed according to standard procedures. Sequences were established using both ABI 377 (PE-Applied Biosystems; dye terminators) and LICOR 4200 (LICOR; dye primers) sequencers. Sequences were assembled using Phred, Phrap (Ewing and Green 1998; Ewing et al. 1998), and Consed (Gordon et al. 1998) software. Finishing, mainly gap filling, and resequencing regions of poor quality (polishing) were performed according to standard methods. Each nucleotide was sequenced at least three times either on both strands or using both dye primer and terminator chemistries.

The assembly of the contigs and their integrity were verified after in silico construction of the "minimum tiling path." Relevant recombinant BACs were analyzed by four restriction endonucleases (BamHI, BglII, HindIII, and XhoI) to confirm their integrity. Also, the restriction map for BssHII and MluI sites was compared to that published by Brugère et al. (2000a). Assignment of contigs to chromosome I was based on known genetic markers (Biderre et al. 1997) and/or by hybridization of Southern blots of E. cuniculi chromosomes separated by pulsed field gel electrophoresis. Blots were hybridized using standard procedures with specific 35-residue-long oligonucleotides labeled with $\left[\alpha-{ }^{32} \mathrm{P}\right] \mathrm{dCTP}$ using terminal transferase (Amersham Pharmacia Biotech).

\section{Sequence Analysis}

The chromosome I consensus sequence was examined for putative ORF using the Glimmer program (Salzberg et al. 1998).
The predicted amino acid sequence (CDS) from each putative ORF was used for BLASTP and PSI-BLAST searches in nonredundant protein databases (www.ncbi.nlm.nih.gov/cgi-bin/ BLAST). Protein domains were determined using Prodom BLAST with graphical output (http://protein.toulouse.inra.fr/ prodom/blast_form.html) and Wise2 (DNA versus Pfam) (http://www.sanger.ac.uk/Software/Wise2/pfamsearch. shtml). Protein structural features were delineated with the SMART program (http://smart.embl-heidelberg.de/) and the PredictProtein server (http://www.embl-heidelberg.de/ predictprotein/). Tandem repeats were identified by Tandem Repeats Finder Program (Benson 1999; http:// c3.biomath.mssm.edu/trf.html) and repeats were screened against a library of repetitive elements using RepeatMasker (http://ftp.genome.washington.edu:80/cgi-bin/ RepeatMasker). Multiple sequence alignments were constructed with CLUSTAL-W (Thompson et al. 1994). Transfer RNAs were identified with tRNAscan-SE (Lowe and Eddy 1997). Motifs discovery was done by the MEME program (http://meme.sdsc.edu/meme/website/). The 199956-bp sequence of chromosome I was submitted to EMBL under the accession no. AL391737.

\section{Telomere-Repeat Determination and Telomere-Associated Sequence Analysis}

Total genomic DNA was treated by Mung Bean nuclease, ligated to a NotI adapter, digested by EcoRI, dephosphorylated and inserted into pGEM-11Zf $\left(^{+}\right)$vector (Promega), restricted by NotI and EcoRI, and gel purified. The recombinant plasmids were sequenced as described. Total E. cuniculi genomic DNA was digested by Bal31 nuclease (New England BioLabs) in a controlled kinetics experiment, restricted by BssHII, electrophoresed on a $0.4 \%$ agarose gel and blotted following acid depurination onto Hybond- $\mathrm{N}^{+}$nylon membranes (Amersham Pharmacia Biotech) in $0.5 \mathrm{M} \mathrm{NaOH}$. The blots were then hybridized with oligonucleotides labeled with $\left[\gamma^{32} \mathrm{ATP}\right]$ by $\mathrm{T}_{4}$ polynucleotide kinase, washed, and submitted to autoradiography against Kodak X-Omat $\mathrm{AR}$ films at $-80^{\circ} \mathrm{C}$ with intensifying screens. Oligonucleotides (5'GGGTCTTCTGGG TCTTCTGGGCCTCCT3', GGGCCTCCGAGCCTTCTGAG CCTTCT, GGGCTTCCTGAGCCTTCTGGGCCTTCT, GAGCC TTGTTTGAGACAGTGTTGCCAGGATGT, and GAGACGCAG TGTTGCCAGGATGTGGG) were designed according to the sequence of the repeats determined in pGEM-11Zf $\left(^{+}\right)$recombinant plasmids.

\section{ACKNOWLEDGMENTS}

We thank G. Méténier for critical reading of the manuscript, P. Brottier and P. Wincker for coordinating the sequence work, B. Chebance and R. Guerry for technical assistance, and Susan Cure for expert reading of the manuscript.

The publication costs of this article were defrayed in part by payment of page charges. This article must therefore be hereby marked "advertisement" in accordance with 18 USC section 1734 solely to indicate this fact.

\section{REFERENCES}

Andersson, B., Aslund, L., Tammi, M., Tran, A.N., Hoheisel, J.D., and Pettersson, U. 1998. Complete sequence of a 93.4-kb contig from chromosome 3 of Trypanosoma cruzi containing a strand-switch region. Genome Res. 8: 809-816.

Ajioka, J.W., Boothroyd, J.C., Brunk, B.P., Hehl, A., Hillier, L., Manger, I.D., Marra, M., Overton, G.C., Roos, D.S., Wan, et al. 1998. Gene discovery by EST sequencing in Toxoplasma gondii 
reveals sequences restricted to the Apicomplexa. Genome Res. 8: $18-28$.

Beauvais, B., Sarfati, C., Challier, S., and Derouin, F. 1994. In vitro model to assess effect of antimicrobial agents on Encephalitozoon cuniculi. Antimicrob. Agents Chemother. 38: 2440-2448.

Benson, G. 1999. Tandem repeats finder: A program to analyze DNA sequences. Nucleic Acids Res. 27: 573-580.

Beverley, S.M., Ellenberger, T.E., and Cordingley, J.S. 1986. Primary structure of the gene encoding the bifunctional dihydrofolate reductase-thymidylate synthase of Leishmania major. Proc. Natl. Acad. Sci. 83: 2584-2588.

Biderre, C., Pages, M., Méténier, G., David, D., Bata, J., Prensier, G., and Vivarès, C.P. 1994. On small genomes in eukaryotic organisms: Molecular karyotypes of two microsporidian species (Protozoa), parasites of vertebrates. C.R. Acad. Sci. III. 317: 399-404.

Biderre, C., Pages, M., Méténier, G., Canning, E.U., and Vivarès, C.P. 1995. Evidence for the smallest nuclear genome $(2.9 \mathrm{Mb})$ in the microsporidium Encephalitozoon cuniculi. Mol. Biochem. Parasitol. 74: $229-231$.

Biderre, C., Duffieux, F., Peyretaillade, E., Glaser, P., Peyret, P., Danchin, A., Pages, M., Méténier, G., and Vivarès, C.P. 1997. Mapping of repetitive and non-repetitive DNA probes to chromosomes of the microsporidian Encephalitozoon cuniculi. Gene 191: 39-45.

Biderre, C., Méténier, G., and Vivarès, C.P. 1998. A small spliceosomal-type intron occurs in a ribosomal protein gene of the microsporidia Encephalitozoon cuniculi. Mol. Biochem. Parasitol. 94: $283-286$.

Biderre, C., Mathis, A., Deplazes, P., Weber, R., Méténier, G., and Vivarès, C.P. 1999a. Molecular karyotype diversity in the microsporidian Encephalitozoon cuniculi. Parasitology 118: 439-445.

Biderre, C., Canning, E.U., Méténier, G., and Vivarès, C.P. 1999b. Comparison of two isolates Encephalitozoon hellem and $E$. intestinalis (Microspora) by pulsed field electrophoresis. Europ. J. Protistol. 35: 194-196.

Bigliardi, E., Riparbelli, M.G., Selmi, M.G., Bini, L., Liberatori, S., Pallini, V., Bernuzzi, A., Gatti, S., Scaglia, M., and Sacchi, L. 1999. Evidence of actin in the cytoskeleton of microsporidia. J. Eukaryot. Microbiol. 46: 410-415.

Bohne, W., Ferguson, D.J., Kohler, K., and Gross, U. 2000. Developmental expression of a tandemly repeated, glycine- and serine-rich spore wall protein in the microsporidian pathogen Encephalitozoon cuniculi. Infect. Immun. 68: 2268-2275.

Bowman, S., Lawson, D., Basham, D., Brown, D., Chillingworth, T., Churcher, C.M., Craig, A., Davies, R.M., Devlin, K., Feltwell, T., et al. 1999. The complete nucleotide sequence of chromosome 3 of Plasmodium falciparum. Nature 400: 532-538.

Brugère, J.F., Cornillot, E., Méténier, G, Bensimon, A, and Vivarès, C.P. 2000a. Encephalitozoon cuniculi (Microspora) genome: Physical map and evidence for telomere-associated rDNA units on all chromosomes. Nucleic Acids Res. 28: 2026-2033.

Brugère, J.F., Cornillot, E., Méténier, G., and Vivarès, C.P. 2000b. Occurrence of subtelomeric rearrangements in the genome of the microsporidian parasite Encephalitozoon cuniculi as revealed by a new fingerprinting procedure based on two-dimensional pulsed field electrophoresis. Electrophoresis 21: 2476-2581.

Cella, R., Nielsen, E., and Parisi, B. 1988. Daucus carota cells contain a dihydrofolate reductase-thymidylate synthase bifunctional polypeptide. Plant Mol. Biol. 10: 331-338.

Coyle, C., Kent, M., Tanowitz, H.B., Wittner, M., and Weiss, L.M. 1998. TNP-470 is an effective antimicrosporidial agent. J. Infect. Dis. 177: 515-518.

Curgy, J.J., Vavra, J., and Vivarès, C. 1980. Presence of ribosomal RNAs with prokaryotic properties in Microsporidia, eukaryotic organisms. Biol. Cell. 38: 49-52.

Day, K.P., Karamalis, F., Thompson, J., Barnes, D.A., Peterson, C., Brown, H., Brown, G.V., and Kemp, D.J. 1993. Genes necessary for expression of a virulence determinant and for transmission of Plasmodium falciparum are located on a 0.3-megabase region of chromosome 9. Proc. Natl. Acad. Sci. 90: 8292-8296.

Delbac, F., Peyret, P., Méténier, G., David, D., Danchin, A., and Vivarès, C.P. 1998. On proteins of the microsporidian invasive apparatus: Complete sequence of a polar tube protein of Encephalitozoon cuniculi. Mol. Microbiol. 29: 825-834.

De Rijk, P., Gatehouse, H.S., and de Wachter, R. 1998. The secondary structure of Nosema apis large subunit ribosomal RNA. Biochim. Biophys. Acta. 1442: 326-328.

Didier, E.S. 1997. Effects of albendazole, fumagillin, and TNP-470 on microsporidial replication in vitro. Antimicrob. Agents Chemother. 41: 1541-1546.

DiMaria, P., Palic, B., Debrunner-Vossbrinck, B.A., Lapp, J., and Vossbrinck, C.R. 1996. Characterization of the highly divergent U2 RNA homolog in the microsporidian Vairimorpha necatrix. Nucleic Acids Res. 24: 515-522.

Dowd, S.E., Gerba, C.P., and Pepper, I.L. 1998. Confirmation of the human-pathogenic microsporidia Enterocytozoon bieneusi, Encephalitozoon intestinalis, and Vittaforma corneae in water. Appl. Environ. Microbiol. 64: 3332-3335.

Duffieux, F., Peyret, P., Roe, B.A., and Vivarès, C.P. 1998. First report on the systematic sequencing of the small genome of Encephalitozoon cuniculi (Protozoa, Microspora): Gene organization of a $4.3 \mathrm{kbp}$ region on chromosome I. Microb. Comp. Genomics 3: 1-11.

Edlind, T.D., Li, J., Visvesvara, G.S., Vodkin, M.H., McLaughlin, G.L., and Katiyar, S.K. 1996. Phylogenetic analysis of beta-tubulin sequences from amitochondrial protozoa. Mol. Phylogenet. Evol. 5: 359-367.

Ewing, B., Hillier, L., Wendl, M.C., and Green, P. 1998. Base-calling of automated sequencer traces using phred. I. Accuracy assessment. Genome Res. 8: 175-185.

Ewing, B. and Green, P. 1998. Base-calling of automated sequencer traces using phred. II. Error probabilities. Genome Res. 8: $186-194$.

Fast, N.M., Roger, A.J., Richardson, C.A., and. Doolittle, W.F. 1998. U2 and U6 snRNA genes in the microsporidian Nosema locustae: Evidence for a functional spliceosome. Nucleic Acids Res. 26: 3202-3207.

Fast, N.M., Logsdon, J.M., Jr, and Doolittle, W.F. 1999. Phylogenetic analysis of the TATA box binding protein (TBP) gene from Nosema locustae: Evidence for a microsporidia-fungi relationship and spliceosomal intron loss. Mol. Biol. Evol. 16: 1415-1419.

Gardner, M.J., Tettelin H., Carucci, D.J., Cummings, L.M., Aravind, L., Koonin, E.V., Shallom, S., Mason, T., Yu, K., Fujii, C., et al. 1998. Chromosome 2 sequence of the human malaria parasite Plasmodium falciparum. Science 282: 1126-1132.

Germot, A., Philippe, H., and Le Guyader, H. 1997. Evidence for loss of mitochondria in Microsporidia from a mitochondrial-type HSP70 in Nosema locustae. Mol. Biochem. Parasitol. 87: 159-168.

Gilson, P.R. and McFadden, G.I. 1997. Good things in small packages: The tiny genomes of chlorarachniophyte endosymbionts. Bioessays 19: 167-173.

Goffeau, A., Barrell, B.G., Bussey, H., Davis, R.W., Dujon, B., Feldmann, H., Galibert, F., Hoheisel, J.D., Jacq, C., Johnston, M., et al. 1996. Life with 6000 genes. Science 274: 563-567.

Gordon, D., Abajian, C., and Green, P. 1998. Consed: A graphical tool for sequence finishing. Genome Res. 8: 195-202.

Hirt, R.P., Healy, B., Vossbrinck, C.R., Canning, E.U., and Embley, T.M. 1997. A mitochondrial Hsp70 orthologue in Vairimorpha necatrix: Molecular evidence that microsporidia once contained mitochondria. Curr. Biol. 7: 995-998.

Hirt, R.P., Logsdon, J.M., Jr, Healy, B., Dorey, M.W., Doolittle, W.F., and Embley, T.M. 1999. Microsporidia are related to Fungi: Evidence from the largest subunit of RNA polymerase II and other proteins. Proc. Natl. Acad. Sci. 96: 580-585.

Kamaishi, T., Hashimoto, T., Nakamura, Y., Masuda, Y., Nakamura, F., Okamoto, K., Shimizu, M., and Hasegawa, M. 1996a. Complete nucleotide sequences of the genes encoding translation elongation factors 1 alpha and 2 from a microsporidian parasite, Glugea plecoglossi: Implications for the deepest branching of eukaryotes. J. Biochem. 120: 1095-1103. 
Kamaishi, T., Hashimoto, T., Nakamura, Y., Nakamura, F., Murata, S., Okada, N., Okamoto, K., Shimizu, M., and Hasegawa, M. 1996b. Protein phylogeny of translation elongation factor EF-1 alpha suggests microsporidians are extremely ancient eukaryotes. J. Mol. Evol. 42: 257-263.

Keeling, P.J. and Doolittle, W.F. 1996. Alpha-tubulin from early-diverging eukaryotic lineages and the evolution of the tubulin family. Mol. Biol. Evol. 13: 1297-1305.

Keohane, E.M., Orr, G.A., Zhang, H.S., Takvorian, P.M., Cali, A., Tanowitz, H.B., Wittner, M., and Weiss, L.M. 1998. The molecular characterization of the major polar tube protein gene from Encephalitozoon hellem, a microsporidian parasite of humans. Mol. Biochem. Parasitol. 94: 227-236.

Liu, S., Widom, J., Kemp, C.W., Crews, C.M., and Clardy, J. 1998. Structure of human methionine aminopeptidase-2 complexed with fumagillin. Science 282: 1324-1327.

Lowe, T.M. and Eddy, S.R. 1997. tRNAscan-SE: A program for improved detection of transfer RNA genes in genomic sequence. Nucleic Acids Res. 25: 955-964.

Mathis, A., Michel, M., Kuster, H. Muller, C., Weber, R., and Deplazes, P. 1997. Two Encephalitozoon cuniculi strains of human origin are infectious to rabbits. Parasitology 114: 29-35.

Myler, P.J., Audleman, L., deVos, T., Hixson, G., Kiser, P., Lemley, C., Magness, C., Rickel, E., Sisk, E., Sunkin, S., et al. 1999. Leishmania major Friedlin chromosome 1 has an unusual distribution of protein-coding genes. Proc. Natl. Acad. Sci. 96: 2902-2906

Pays, E. and Nolan, D.P. 1998. Expression and function of surface proteins in Trypanosoma brucei. Mol. Biochem. Parasitol. 91: 3-36.

Peyretaillade, E., Biderre, C., Peyret, P., Duffieux, F., Méténier, G., Gouy, M., Michot, B., and Vivarès, C.P. 1998a. Microsporidian Encephalitozoon cuniculi, a unicellular eukaryote with an unusual chromosomal dispersion of ribosomal genes and a LSU rRNA reduced to the universal core. Nucleic Acids Res. 26: 3513-3520.

Peyretaillade, E., Broussolle, V., Peyret, P., Méténier, G., Gouy, M., and Vivarès, C.P. 1998b. Microsporidia, amitochondrial protists, possess a 70-kDa heat shock protein gene of mitochondrial evolutionary origin. Mol. Biol. Evol. 15: 683-689.

Pologe, L.G. and Ravetch, J.V. 1986. A chromosomal rearrangement in a $P$. falciparum histidine-rich protein gene is associated with the knobless phenotype. Nature 322: 474-477.

Radisky, D.C., Babcock, M.C., and Kaplan, J. 1999. The yeast frataxin homologue mediates mitochondrial iron cycle. J. Biol. Chem. 274: $4497-4499$.

Raynaud, L., Delbac, F., Broussolle, V., Rabodonirina, M., Girault, V., Wallon, M., Cozon, G., Vivarès, C.P., and Peyron, F. 1998. Identification of Encephalitozoon intestinalis in travelers with chronic diarrhea by specific PCR amplification. J. Clin. Microbiol. 36: $37-40$.

Salzberg, S.L., Delcher, A.L., Kasif, S., and White, O. 1998. Microbial gene identification using interpolated Markov models. Nucleic Acids Res. 26: 544-548.

Sandfort, J., Hannemann, A., Gelderblom, H., Stark, K., Owen, R.L., and Ruf, B. 1994. Enterocytozoon bieneusi infection in an immunocompetent patient who had acute diarrhea and who was not infected with the human immunodeficiency virus. Clin. Infect. Dis. 19: 514-516.

Schilke, B., Voisine, C., Beinert, H., and Craig, E. 1999. Evidence for a conserved system for iron metabolism in the mitochondria of Saccharomyces cerevisiae. Proc. Natl. Acad. Sci. 96: 10206-10211.

Sin, N., Meng, L., Wang, M.Q., Wen, J.J., Bornmann, W.G., and Crews, C.M. 1997. The anti-angiogenic agent fumagillin covalently binds and inhibits the methionine aminopeptidase, MetAP-2. Proc. Natl. Acad. Sci. 94: 6099-6103.

Singer, M.A. and Lindquist, S. 1998. Thermotolerance in Saccharomyces cerevisiae: The Yin and Yang of trehalose. Trends Biotechnol. 16: 460-468.

The C. elegans sequencing consortium. 1998. Genome sequence of the nematode C. elegans: A platform for investigating biology. Science 282: 2012-2018.

Thompson, J.D., Higgins, D.G., and Gibson, T.J. 1994. CLUSTAL W: Improving the sensitivity of progressive multiple sequence alignment through sequence weighting, position-specific gap penalties, and weight matrix choice. Nucleic Acids Res. 22: 4673-4680.

Undeen, A.H. 1990. A proposed mechanism for the germination of microsporidian (Protozoa: Microspora) spores. J. Theor. Biol. 142: 223-235.

Undeen, A.H. and van der Meer, R.K. 1999. Microsporidian intrasporal sugars and their role in germination. J. Invertebr. Pathol. 73: 294-302.

Van de Peer, Y., Ben Ali, A., and Meyer, A. 2000. Microsporidia: Accumulating molecular evidence that a group of amitochondriate and suspectedly primitive eukaryotes are just curious fungi. Gene 246: 1-8.

Vossbrinck, C.R. and Woese, C.R. 1986. Eukaryotic ribosomes that lack a 5.8S RNA. Nature 320: 287-288.

Vossbrinck, C.R., Maddox, J.V., Friedman, S., Debrunner-Vossbrinck, B.A., and Woese, C.R. 1987. Ribosomal RNA sequence suggests microsporidia are extremely ancient eukaryotes. Nature 326: 411-414.

Weidner, E., Findley, A.M., Dolgikh, V., and Sokolova, J. 1999. Microsporidian biochemistry and physiology. In The microsporidia and microsporidiosis (ed. M. Wittner, contributing ed. L.M. Weiss), pp. 172-195. American Society for Microbiology, Washington, D.C.

Weiss, L.M. and Vossbrinck, C. 1999. Molecular biology, molecular phylogeny, and molecular diagnostic approaches to the microsporidia. In The microsporidia and microsporidiosis (ed. M. Wittner, contributing ed. L.M. Weiss), pp. 129-171. American Society for Microbiology, Washington, D.C.

Zauner, S., Fraunholz, M., Wastl, J., Penny, S., Beaton, M., Cavalier-Smith, T., Maier, U.G., and Douglas, S. 2000. Chloroplast protein and centrosomal genes, a tRNA intron, and odd telomeres in an unusually compact eukaryotic genome, the cryptomonad nucleomorph. Proc. Natl. Acad. Sci. 97: 200-205.

Received September 8, 2000; accepted in revised form November 8, 2000.
Genome Research www.genome.org 


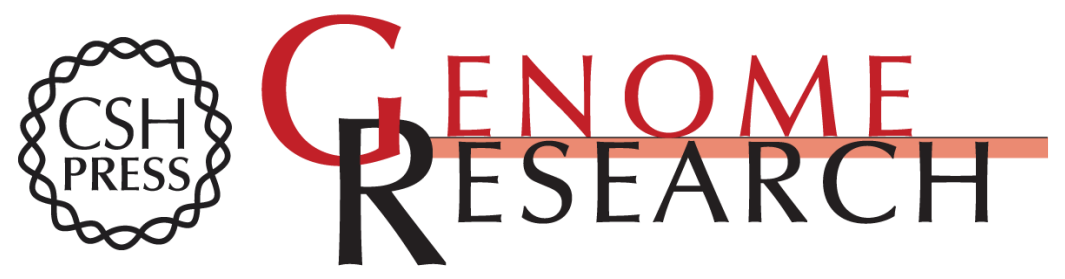

\section{Sequence and Analysis of Chromosome I of the Amitochondriate Intracellular Parasite Encephalitozoon cuniculi (Microspora)}

Pierre Peyret, Michael D. Katinka, Simone Duprat, et al.

Genome Res. 2001 11: 198-207

Access the most recent version at doi:10.1101/gr.164301

References This article cites 63 articles, 20 of which can be accessed free at:

http://genome.cshlp.org/content/11/2/198.full.html\#ref-list-1

\section{License}

Email Alerting Receive free email alerts when new articles cite this article - sign up in the box at the Service top right corner of the article or click here.

\section{Affordable, Accurate Sequencing.}

